\title{
The clinicopathological significance of monocarboxylate transporters in testicular germ cell tumors
}

\author{
Eduardo C.A. Silva ${ }^{1}$, Flavio M. Cárcano ${ }^{2,3}$, Murilo Bonatelli, ${ }^{4}$ Maurício G. Zaia ${ }^{4}$, Filipa \\ Morais-Santos ${ }^{5,6}$, Fátima Baltazar ${ }^{5,6}$, Luiz F. Lopes ${ }^{3,7}$, Cristovam Scapulatempo- \\ Neto $^{1,4}$ and Céline Pinheiro ${ }^{3,4}$ \\ ${ }^{1}$ Pathology Department, Barretos Cancer Hospital, Barretos, São Paulo, Brazil \\ ${ }^{2}$ Medical Oncology Department, Barretos Cancer Hospital, Barretos, São Paulo, Brazil \\ ${ }^{3}$ Barretos School of Health Sciences Dr. Paulo Prata - FACISB, Barretos, São Paulo, Brazil \\ ${ }^{4}$ Molecular Oncology Research Center, Barretos Cancer Hospital, Barretos, São Paulo, Brazil \\ ${ }^{5}$ Life and Health Sciences Research Institute (ICVS), School of Health Sciences, University of Minho, Braga, Portugal \\ ${ }^{6}$ ICVS/3B's-PT Government Associate Laboratory, Braga/Guimarães, Portugal \\ ${ }^{7}$ Barretos Children's Cancer Hospital, Barretos, São Paulo, Brazil \\ Correspondence to: Céline Pinheiro, email: celinepinheiro@gmail.com \\ Keywords: testicular neoplasms; testicular germ cell tumors; monocarboxylate transporter; immunohistochemistry; Warburg effect \\ Received: August 26, $2016 \quad$ Accepted: February 26, $2018 \quad$ Published: April 17, 2018 \\ Copyright: Silva et al. This is an open-access article distributed under the terms of the Creative Commons Attribution License 3.0 \\ (CC BY 3.0), which permits unrestricted use, distribution, and reproduction in any medium, provided the original author and source \\ are credited.
}

\section{ABSTRACT}

Background: Metabolic reprogramming is one of the hallmarks of cancer. The hyperglycolytic phenotype is often associated with the overexpression of metabolismassociated proteins, such as monocarboxylate transporters (MCTs). MCTs are little explored in germ cell tumors (GCTs), thus, the opportunity to understand the relevance of these metabolic markers and their chaperone CD147 in this type of tumor arises. The main aim of this study was to evaluate the expression of MCT1, MCT2, MCT4 and CD147 in testicular GCT samples and the clinicopathological significance of these metabolism related proteins.

Results: MCT1, MCT4 and CD147 were associated with higher stages, higher M and $\mathbf{N}$ stages and histological type, while MCT4 was also associated with higher risk stratification, presence of vascular invasion, and lower overall and event free survival. MCT4 silencing in JEG-3 had no significant effect in cell viability, proliferation and death, as well as extracellular levels of glucose and lactate. However, MCT4-silenced cells showed an increase in migration and invasion.

Conclusion: The proteins herein studied, with the exception of MCT2, were associated with characteristics of worse prognosis, lower global and event free survival of patients with GCTs. Also, in vitro MCT4 silencing stimulated cell migration and invasion.

Materials and Methods: Immunohistochemical expression was evaluated on samples from 149 adult patients with testicular GCT, arranged in Tissue Microarrays (TMAs), and associated with the clinicopathological data. Also, MCT4 silencing studies using siRNA were performed in JEG-3 cells.

\section{INTRODUCTION}

Although testicular germ cell tumors (TGCTs) are relatively rare neoplasms, they are the most frequent solid tumors affecting young males $[1,2]$. Importantly, the natural history of these tumors has changed over the past three decades, thanks to platinum-based chemotherapy regimens, with current 5-year overall survival rates 
over $90 \%$ regardless of histological type (seminoma and nonseminomatous) and cure rates over $90 \%$ in the low risk group. Although the majority of patients with TGCTs have good responses to treatment, some of them resist to therapy and present disease progression (reviewed in $[3,4])$. Therefore, it is important to better understand the biological heterogeneity of TGCTs, in order to optimize treatment by exploring new pathways involved in tumor development and progression.

Nearly all TGCTs present the isochromosome 12p, which has been pointed as the triggering event leading to invasive growth in TGCTs. However, the precise functional mechanisms involving isochromosome $12 \mathrm{p}$ as a player in TGCTs are yet to be described (reviewed in [5]). Despite this lack of information, other relevant biological characteristics involved in the multistep development of human tumors, as proposed by Hanahan and Weinberg [6], should be considered in the pursuit to a better understanding of the biological features of TGCTs. In this context, the reprogramming of energy metabolism, recently described as one of the hallmarks of cancer cells $[6,7]$, emerges as a promising candidate.

Malignant cells tend to have a hyperglycolytic phenotype, a metabolic reprogramming in which cancer cells have a preference for energy production through glycolysis, even in the presence of oxygen, a phenomenon called the Warburg effect $[8,9]$. This phenotype leads to greater consumption of glucose and produces more lactate than the normal metabolic profile, which depends mostly on oxidative phosphorylation [6-9]. To avoid intracellular acidification due to this altered metabolism, some proteins are upregulated, including monocarboxylate transporters (MCTs), which are also responsible for lactate transport [10]. MCTs belong to a family that comprises 14 different isoforms, from which only MCT1-4 have been described as lactate transporters: isoforms 1 and 4 are mainly associated with lactate efflux and their main chaperone is CD147 [11-13], MCT2 is involved in lactate influx and its chaperone is gp $70[14,15]$. In fact, many different types of cancer overexpress MCT1, MCT4 and CD147, and this overexpression is associated with worse prognosis [1624]. As pointed out by many studies, these proteins may play a relevant role as prognostic markers and be explored as possible therapeutic targets [24-31].

Although studies evaluating MCTs in TGCTs are lacking, there is evidence that these tumors are highly glycolytic, as they overexpress glucose transporter 3 (GLUT3) [32, 33], a protein often expressed by malignant neoplasms [33, 34], and, importantly, their high glucose consumption rates are demonstrated by ${ }^{18}$ F-Fluorodeoxyglucose positron emission tomography studies [35-37].

Since MCTs need to be more explored, including in TGCTs, it is important to evaluate the relevance of these metabolic markers and the chaperone CD147 in this type of tumor. Therefore, the aims of this study were to evaluate the expression of MCT1, MCT2, MCT4 and CD147 in normal tissues and TGCTs, using tissue microarrays (TMAs), to validate the TMA method for the study of these proteins in a heterogeneous type of tumor, to compare the expression in tumors with normal tissue, to correlate the expression with clinicopathological data, and to further explore the contribution of MCTs for tumor aggressiveness using GCT in vitro models.

\section{RESULTS}

\section{Immunohistochemistry expression and cutoffs}

The immunohistochemical expression was graduated in extension (percent of positive cells) and intensity (negative/weak/moderate/intense). Cutoffs for positivity of each marker were defined based on the area under the ROC curve, considering the sum of scores and the occurence of clinical event (recurrence, progression or death). For MCT1 and MCT4, the score with best sensitivity and specificity was 6 , while for MCT2 it was 3 and for CD147 it was 5 (Table 1).

As can be observed in Figure 1, MCT1, MCT4 and CD147 were observed at the plasma membrane, while MCT2 was mostly detected only at the cytoplasm.

\section{Validation of TMA method}

Analysis of agreement between TMA and whole tissue sections showed an accuracy for TMA method of $79.3 \%$ for MCT1, 100\% for MCT2, $76.6 \%$ for MCT4 and $79.3 \%$ for CD147.

\section{Clinicopathological significance of MCTs and CD147}

When compared to paired normal tissue samples (Figure 2), TGCTs significantly overexpressed MCT4 $(p=0.001)$ and CD147 $(p=0.001)$.

Table 2 shows the associations between the expression of the metabolism related proteins and the clinicopathological parameters of the patients. MCT1 expression showed a statistically significant association with higher $\mathrm{N}$ stages $(p=0.015)$, higher $\mathrm{M}$ stage $(p=0.002)$, stages higher than I $(p=0.001)$, and nonseminomatous histology $(p<0.001)$. MCT4 was associated with higher T stages $(p=0.004)$, higher M stage $(p=0.037)$, stages higher than I $(p=0.045)$, presence of vascular invasion ( $p=0.002)$, nonseminomatous histology $(p<0.001)$, and higher International Germ Cell Cancer Collaborative Group (IGCCG) risk stratifications ( $p=$ $0.030)$. CD147 was associated with stages higher than I $(p=0.003)$, higher $\mathrm{N}$ stages $(p=0.022)$, higher $\mathrm{M}$ stage $(p=0.020)$, and nonseminomatous histology $(p<0.001)$. In opposition, MCT2 showed no association with the clinicopathological data. 
Table 1: Markers' cutoffs based on the area under the ROC curve, and their classification measures

\begin{tabular}{lcccccc}
\hline Marker & Cutoff & Sensitivity (\%) & Specificity (\%) & PPV & NPV & Area under ROC curve (CI) \\
\hline MCT1 & $\geq 6$ & 64.0 & 53.8 & 22.5 & 87.7 & $0.597(0.479-0.715)$ \\
MCT2 & $\geq 3$ & 14.3 & 84.4 & 16.7 & 81.8 & $0.509(0.264-0.754)$ \\
MCT4 & $\geq 6$ & 69.6 & 55.1 & 23.2 & 90.3 & $0.647(0.537-0.758)$ \\
CD147 & $\geq 5$ & 35.0 & 77.5 & 25.9 & 84.1 & $0.557(0.416-0.698)$ \\
\hline
\end{tabular}

CI - Confidence interval; PPV - Positive predictive value; NPV - Negative predictive value.

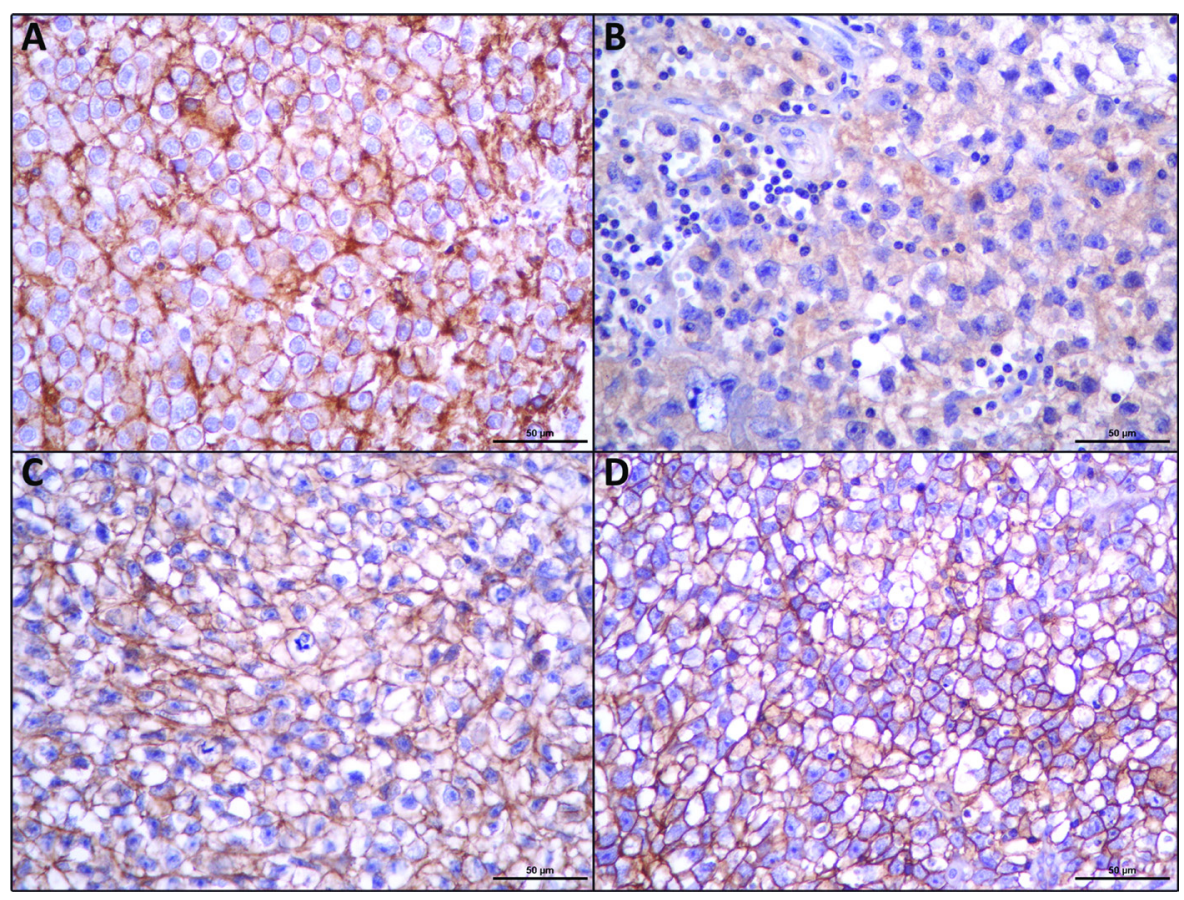

Figure 1: Immunohistochemical expression of MCT1 (A), MCT2 (B), MCT4 (C), CD147 (D), in seminomas. MCT2 shows cytoplasmic staining while the other proteins show an evident plasma membrane expression.

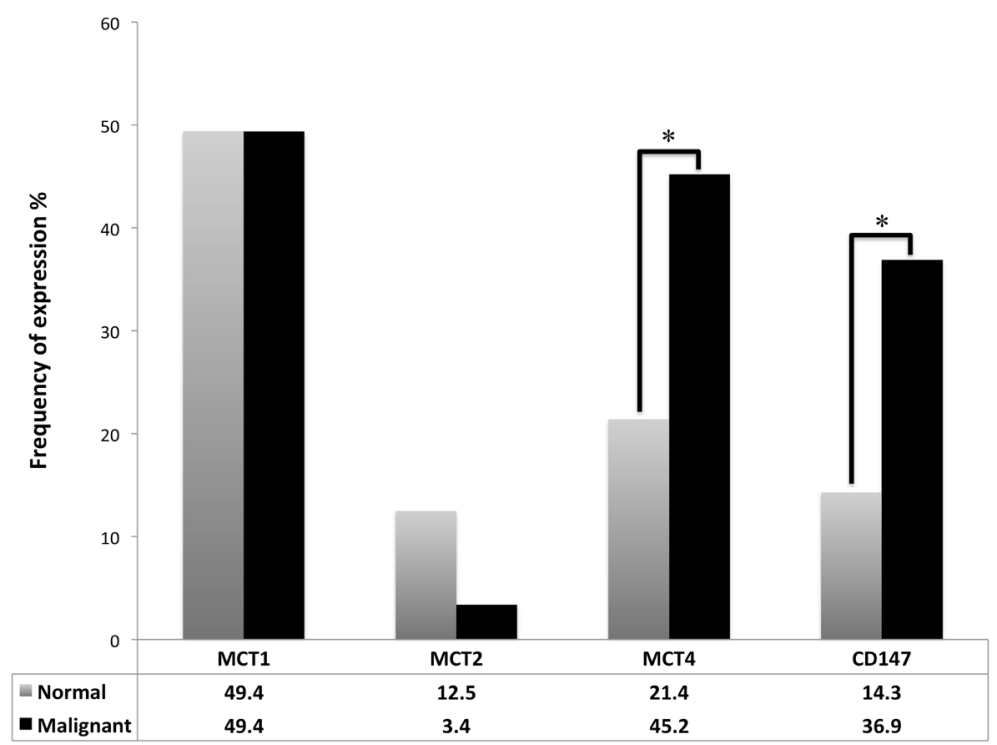

Figure 2: Frequency of plasma membrane expression of MCT1, MCT2, MCT4 and CD147 in TGCTs and normal testicular tissue. McNemar's test was used to assess differences of expression frequency between tumor and normal tissue. ${ }^{*} p=0.001$. 
Table 2: Association of MCT1, MCT2, MCT4 and CD147 expression with clinicopathological parameters

\begin{tabular}{|c|c|c|c|c|c|c|c|c|c|c|c|c|}
\hline & & MCT1 & & MC & & & MCT & & & & CD147 & \\
\hline & $n$ & Positive (\%) & $p$ & $n$ & Positive (\%) & $p$ & $n$ & $\begin{array}{c}\text { Positive } \\
(\%)\end{array}$ & $p$ & $n$ & Positive (\%) & $p$ \\
\hline T stage & & & 0.148 & & & $0.081^{*}$ & & & 0.004 & & & $0.069^{*}$ \\
\hline $\mathrm{T} 1$ & 85 & $35(41.2)$ & & 85 & $5(5.9)$ & & 83 & $29(34.9)$ & & 82 & $25(30.5)$ & \\
\hline $\mathrm{T} 2+\mathrm{T} 3+\mathrm{T} 4$ & 58 & $31(53.4)$ & & 58 & $0(0.0)$ & & 57 & $34(59.6)$ & & 57 & $26(45.6)$ & \\
\hline N stage & & & 0.015 & & & $1.000^{*}$ & & & 0.094 & & & $0.022^{*}$ \\
\hline N0 & 84 & $33(39.3)$ & & 83 & $4(4.8)$ & & 81 & $33(40.7)$ & & 80 & $23(28.8)$ & \\
\hline $\mathrm{N} 1+\mathrm{N} 2+\mathrm{N} 3$ & 62 & $37(59.7)$ & & 62 & $2(3.2)$ & & 62 & $34(54.8)$ & & 60 & $29(47.5)$ & \\
\hline M stage & & & 0.002 & & & $1.000^{*}$ & & & 0.037 & & & $0.020^{*}$ \\
\hline M0 & 122 & $52(42.6)$ & & 121 & $5(4.1)$ & & 120 & $52(43.3)$ & & 118 & $39(33.1)$ & \\
\hline M1 & 25 & $19(76.0)$ & & 25 & $1(4.0)$ & & 24 & $16(66.7)$ & & 24 & $14(58.3)$ & \\
\hline Stage & & & 0.001 & & & $1.000^{*}$ & & & 0.045 & & & $0.003^{*}$ \\
\hline I & 74 & $26(35.1)$ & & 73 & $3(4.1)$ & & 72 & $28(38.9)$ & & 71 & $18(25.4)$ & \\
\hline IS+II+III+IV & 73 & 45 (61.6) & & 73 & $3(4.1)$ & & 72 & $40(55.6)$ & & 71 & $35(49.3)$ & \\
\hline Vascular invasion & & & 0.889 & & & $0.178^{*}$ & & & 0.002 & & & $0.493^{*}$ \\
\hline No & 99 & $45(45.5)$ & & 99 & $6(6.1)$ & & 97 & $35(36.1)$ & & 96 & $33(34.4)$ & \\
\hline Yes & 43 & $19(44.2)$ & & 43 & $0(0.0)$ & & 42 & $27(64.3)$ & & 42 & $17(40.5)$ & \\
\hline Histology & & & $<0.001$ & & & $0.114^{*}$ & & & $<0.001$ & & & $<0.001^{*}$ \\
\hline Seminoma & 75 & $17(22.7)$ & & 75 & $1(1.3)$ & & 73 & $23(31.5)$ & & 73 & $10(13.7)$ & \\
\hline Nonseminomatous & 74 & $54(73.0)$ & & 73 & $5(6.8)$ & & 73 & $46(63.0)$ & & 71 & $43(60.6)$ & \\
\hline IGCCG Risk & & & $0.194^{*}$ & & & $0.452^{*}$ & & & $\mathbf{0 . 0 3 0} 0^{*}$ & & & $0.801^{*}$ \\
\hline Low & 45 & $26(57.8)$ & & 45 & $2(4.4)$ & & 45 & $21(46.7)$ & & 44 & $22(50.0)$ & \\
\hline Intermediate & 11 & 7 (63.6) & & 11 & $0(0.0)$ & & 11 & $8(72.7)$ & & 11 & 7 (63.6) & \\
\hline High & 10 & $9(90.0)$ & & 10 & $1(10.0)$ & & 9 & $8(88.9)$ & & 9 & $5(55.6)$ & \\
\hline Recurrence & & & 0.108 & & & $0.542^{*}$ & & & 0.303 & & & $0.682^{*}$ \\
\hline No & 125 & $55(44.0)$ & & 125 & $5(4.0)$ & & 123 & $56(45.5)$ & & 122 & $44(36.1)$ & \\
\hline Yes & 17 & $11(64.7)$ & & 17 & $1(5.9)$ & & 17 & $10(58.8)$ & & 17 & $7(41.2)$ & \\
\hline Progression & & & $0.468^{*}$ & & & $0.287^{*}$ & & & $0.725^{*}$ & & & $1.000^{*}$ \\
\hline No & 68 & $40(58.8)$ & & 68 & $2(2.9)$ & & 68 & $37(54.4)$ & & 67 & $31(46.3)$ & \\
\hline Yes & 8 & $6(75.0)$ & & 8 & $1(12.5)$ & & 8 & $5(62.5)$ & & 8 & $4(50.0)$ & \\
\hline
\end{tabular}

"Fisher's exact test.

\section{MCTs, CD147 and survival}

Kaplan-Meier analysis (Figure 3) revealed that MCT4 positive expression was significantly associated with shorter overall $(p=0.011)$ as well as shorter event-free survival $(p=0.027)$. Other proteins were not significantly associated with survival. None of the markers were associated with survival in multivariate analysis by Cox regression (data not shown).

\section{In vitro experiments}

To further elucidate the possible contribution of MCT4 for tumor aggressiveness, in vitro MCT4 silencing studies were performed.

First, the germ cell tumor cell lines JEG-3 and NTERA-2 were characterized for MCT and CD147 expression. As can be seen in Figure 4A, MCT1, MCT4 and CD147 were expressed at the plasma membrane of both cell lines, although MCT4 was only detected in a small proportion of NTERA-2 cells. In opposition, MCT2 was absent from both JEG-3 and NTERA-2 cell lines. These results were validated by Western-blot (Figure 4B). Based on these results, JEG-3 cells were selected for MCT4 silencing using siRNA (Figure 5A). As depicted in Figure 5, MCT4 silencing had no effect on extracellular amounts of glucose (Figure 5B) and lactate (Figure 5C), as well as no effect of cell viability (Figure 5D), proliferation (Figure 5E) and death (Figure 5F). However, as can be seen in Figure 6, MCT4-silenced cells showed an important increase in migration (Figure 6A) and invasion (Figure 6B).

\section{DISCUSSION}

In the present study, the expression of the metabolism related proteins MCT1, MCT2, MCT4 and 
CD147 was characterized in a representative sample of testicular TGCTs.

The use of the area under ROC curve to access the cutoffs for positivity allowed the definition of scores better associated with clinical events of recurrence, progression and death. The cutoffs defined were MCT $1 \geq 6$, MCT $2 \geq 3$, MCT4 $\geq 6$ and CD147 $\geq 5$. With the exception of MCT2, these scores differ from the ones used in previous studies by our group, where scores $\geq 3$ were defined as positive [ 19 , 38-51]. We believe that this approach for cutoff definition, which may vary among tumor type but is more illustrative of possible clinical significance, may bring results that, otherwise, may be masked by an inadequate cutoff.

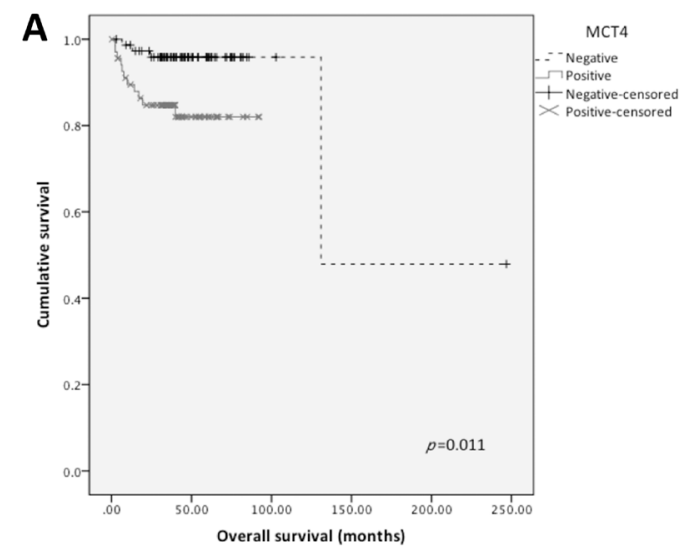

TMA method demonstrated an accuracy of 79.3\% for MCT1, 100\% for MCT2, 76.6\% for MCT4 and 79.3\% for CD147. A potential limitation of this method is tumor heterogeneity, a common event in GCTs. However, in this study, cores in triplicate for each histological subtype were used, in attempt to minimize this limitation. This study is similar to others in the way that evaluated GCTs by immunohistochemistry on TMAs with cores in triplicate $[32,52]$; however, those and other previous studies using TMAs to organize GCTs did not compare TMAs with whole sections $[32,52,53]$. The present study is unique since it used triplicate cores for each histological subtype and compared 31 whole sections in a sample of 149

Figure 3: Overall and event-free survival curves of TGCTs' patients. Only significant results are shown. Continuous line refers to positive expression while interrupted line refers to negative expression. (A) Overall survival associated with MCT4 plasma membrane expression; (B) Event-free survival associated with MCT4 plasma membrane expression.

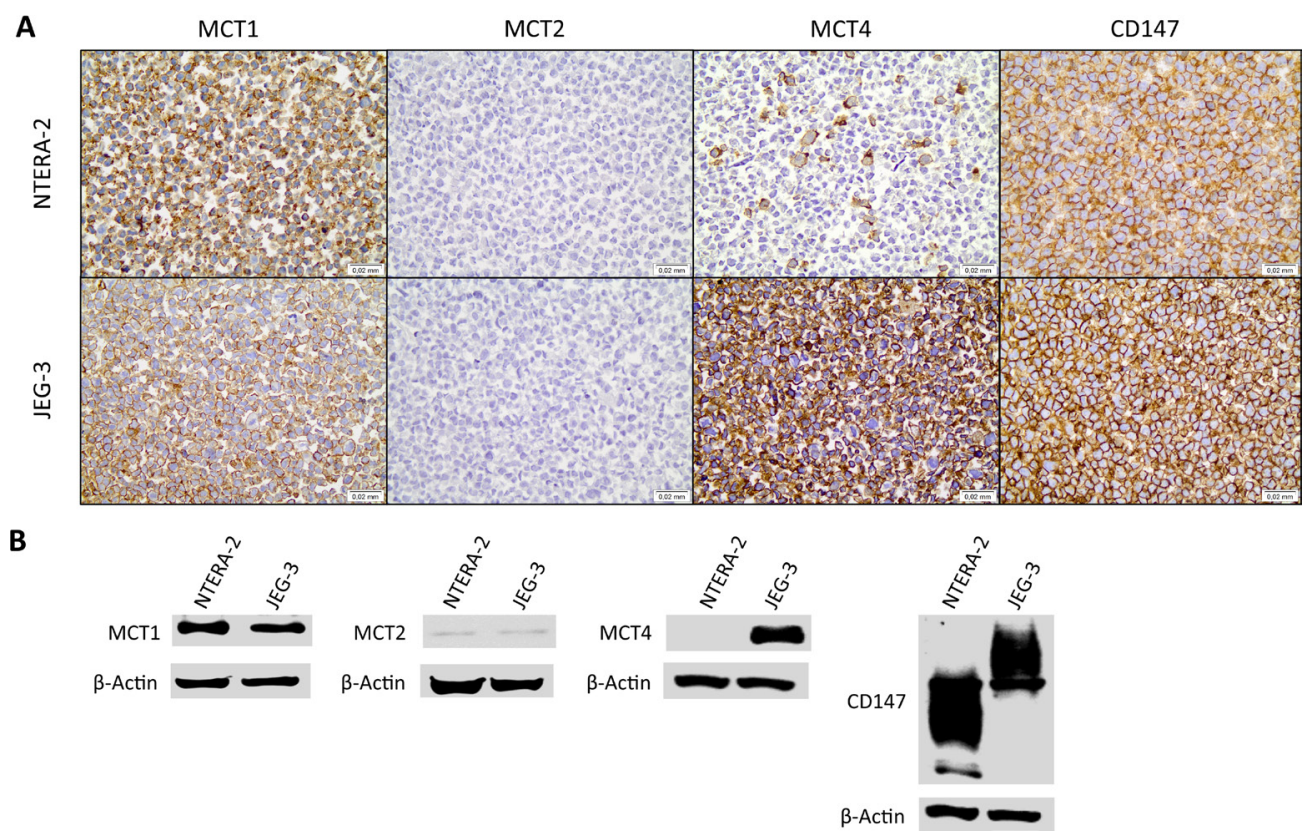

Figure 4: Expression of monocarboxylate transporters and the chaperone CD147 in the germ cell tumor cell lines JEG-3 and NTERA-2. (A) Immunocytochemical expression of MCT1, MCT2, MCT4 and CD147; (B) Detection of MCT1, MCT2, MCT4 and CD147 by Western blot, in cell lysates. 
cases on TMAs, achieving acceptable accuracy values, considering tumor heterogeneity.

MCT4 and CD147 overexpression in TGCTs, when compared to normal tissue, suggests that these tumor cells present a high lactate efflux, most probably as a result of a hyperglycolytic phenotype. These findings are in line with previous data that associate the overexpression of these proteins with hyperglycolytic phenotypes in other tumor
A

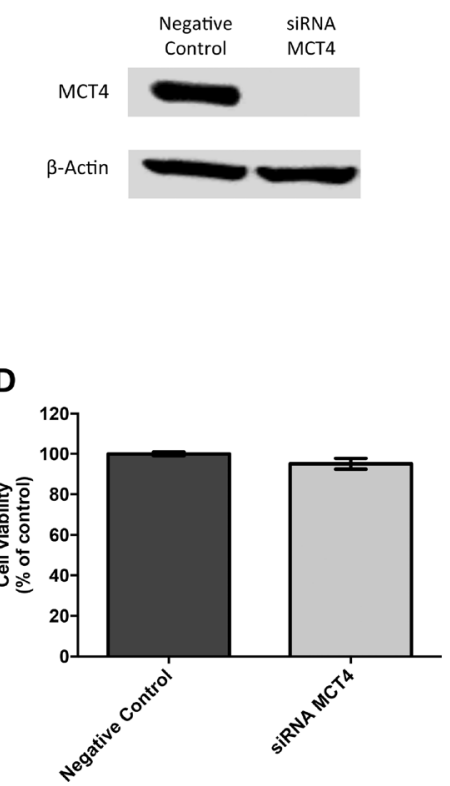

B

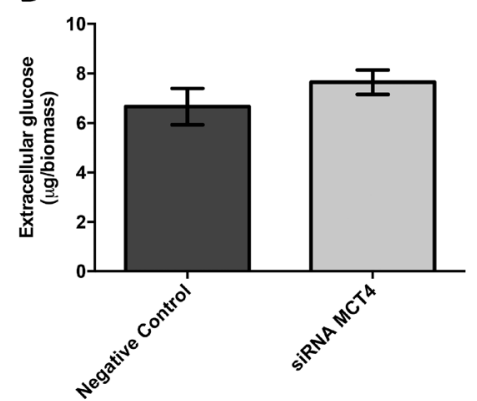

E

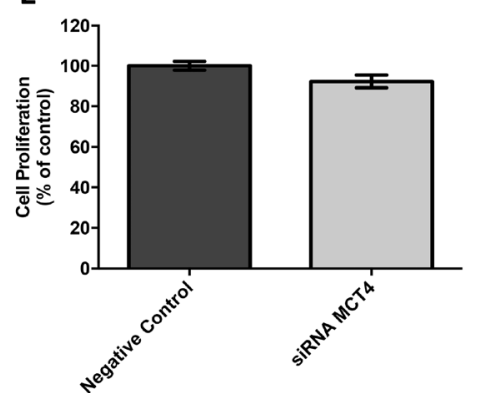

C

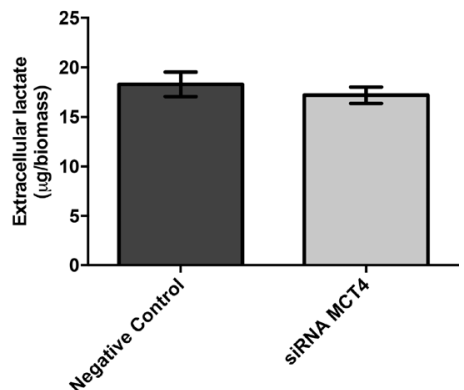

$\mathbf{F}$

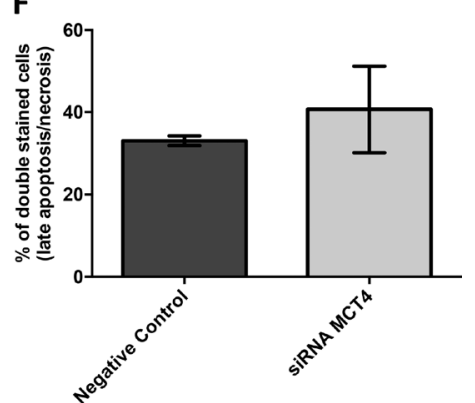

Figure 5: MCT4 silencing had no effect on metabolic parameters as well as viability, proliferation and death of JEG-3 cells. (A) Western blot results for MCT4 expression after SLC16A3 knockdown, using $10 \mathrm{nM}$ siRNA, for 72 hours, showing an effective silencing of MCT4 expression. Scramble siRNA was used as negative control and $\beta$-actin was used as loading control. Extracellular amounts of glucose (B) and lactate $(\mathbf{C})$ levels were quantified in culture medium obtained after 24 hours, normalized by total biomass (obtained using SRB assay) and are represented as the mean of three independent experiments in triplicate \pm SEM. Cell viability was evaluated using SRB assay (D) while cell proliferation was evaluated using BrdU incorporation (E). Results were obtained after 24 hours of cell culture, normalized as the percentage of the negative control (scramble siRNA), and are represented as the mean of three independent experiments in triplicate \pm SEM. Cell death was evaluated using flow cytometry analysis after Annexin V/PI staining (F). Results were obtained after 24 hours and are represented by the mean percentage of double stained cells (late apoptosis/necrosis) from two independent experiments \pm SEM.
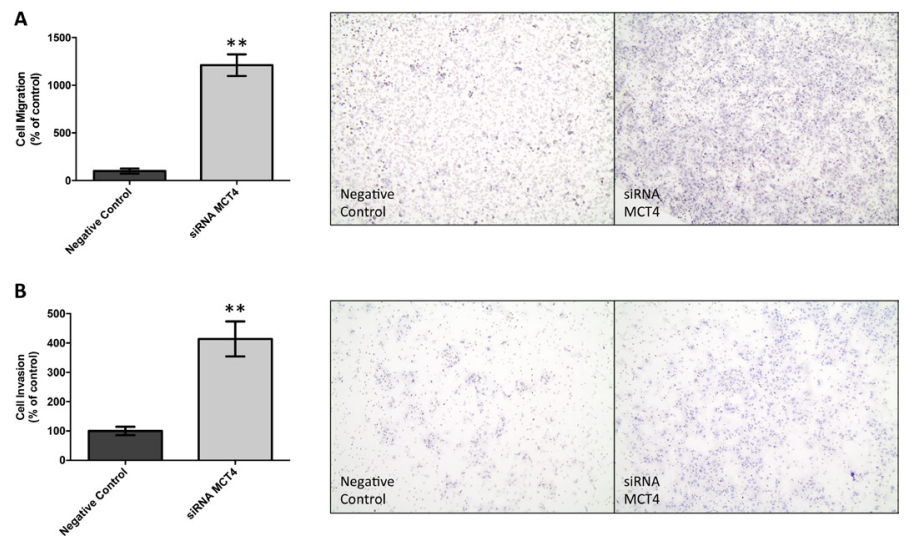

Figure 6: MCT4 silencing increases cell migration and invasion of JEG-3 cells. Cell migration was evaluated using ThinCert Cell Cultures Inserts (Greiner Bio-One) (A). Results were obtained after 24 hours and are represented as the mean of two independent experiments in duplicate \pm SEM (left panel). Representative images of the migration assay are shown (right panel). ${ }^{* *} p=0.0016$ compared to control (scramble siRNA). Cell invasion was evaluated using Corning BioCoat Matrigel Invasion Chamber with BD Matrigel Matrix (B). Results were obtained after 24 hours and are represented as the mean of three independent experiments in duplicate \pm SEM (left panel). Representative images of the invasion assay are shown (right panel). ${ }^{* *} p=0.0027$ compared to control (scramble siRNA). 
types, being associated with malignant behavior and tumor aggressiveness [17, 19, 21, 22, 28, 54]. Although not statistically significant, the higher expression of MCT2 in normal tissue than in TGCTs is consistent with its function in lactate uptake, and with the oxidative phenotype of normal tissues [11, 14, 19, 55].

The association of MCT1, MCT4 and CD147 expression with characteristics of worse prognosis, such as nonseminomatous histology, higher stages, higher metastasis occurrence, vascular invasion and higher risk stratification, reflect the function of these proteins in lactate efflux, in maintaining the extracellular acid $\mathrm{pH}$, and, as a result, in glycolytic phenotype and tumor aggressiveness. Despite the lack of studies of these proteins on TGCTs, our findings corroborate previous evidence of the association between their expression and worse prognosis in other types of cancer with glycolytic phenotype [16, 18, 54, 56, 57].

MCT4 expression was associated with lower overall and event free survival in univariate analysis, which is consistent with previous findings in other solid tumors [16, $18,22,54,56-58]$. However, none of the markers were associated with lower survival in multivariate analysis.

Previous studies have shown that, in general, in vitro MCT silencing is associated with a decrease in tumor cell aggressiveness, by means of a decrease in cell viability, proliferation, migration and invasion as well as an increase in cell death (reviewed in [24]), which would support the findings obtained in the TGCTs human samples. Herein, MCT4 silencing did not affect cell viability, proliferation or death. In fact, this is not an unexpected result, as the cell line used for MCT4 silencing also express MCT1 at the plasma membrane, which is probably providing the efflux of lactate, compensating for the lack of MCT4. Actually, accordingly, extracellular glucose and lactate levels were not affected by MCT4 silencing, an observation already made in other in vitro tumor model [28]. To validate this hypothesis, an attempt to a double MCT1/MCT4 silencing approach was made, however, the different timings of MCT1 versus MCT4 silencing using siRNA, compromised the efficiency of the double silencing (Supplementary Figure 1A and 1B). Other experimental approaches, such as stable silencing or gene editing, are warranted to further explore this hypothesis. Nevertheless, although with no influence on extracellular glucose and lactate, cell viability, proliferation and death, MCT4 silencing importantly increased cell migration and invasion. Previous studies have showed a role of MCT1 and MCT4 in tumor cell migration [23, 59-63] and invasion $[62,64]$, which seems to be independent from transporter activity [60]. Following this line of evidence, and considering that the result expected from MCT4 silencing is a reduction in cell migration and invasion, one can hypothesize that the increase in these parameters may result from an increase in MCT1 expression in response to MCT4 silencing. However, neither MCT1 nor CD147 expression was altered by MCT4 silencing (Supplementary Figure 1D). Additional studies are needed to further explore the specific contribution of MCT4 for tumor cell migration and invasion in germ cell tumors and others.

In conclusion, the present study validates TMA as a useful method to study MCTs and CD147 in TGCTs. Also, it demonstrates the overexpression of these proteins in tumor cells, and its association with parameters of worse prognosis and shorter survival rates. Finally, in vitro studies showed that individual MCT4 silencing in a cell line positive for both MCT1 and MCT4 does not decrease the main parameters of tumor aggressiveness. This study may contribute to the knowledge on the clinicopathological significance of these metabolismrelated proteins and paves the way for additional studies to explore them as potential prognostic markers and possible therapeutic targets in TGCTs.

\section{MATERIALS AND METHODS}

\section{Cases selection}

A total of 149 cases of TGCTs were selected from the Department of Pathology of Barretos Cancer Hospital. Only samples from primary tumors, collected prior to chemotherapy and with enough formalin fixed paraffin embedded material, were selected.

The clinicopathological data collected included age, date of diagnosis, histological types, grading (when applicable), staging (TNM), presence of vascular invasion, IGCCG risk stratification, and dates of surgery, chemotherapy, recurrence and death.

Patients' mean age was 32.3 years (ranging from 18 to 73 years) and most of them were Caucasian (80.2\%). As depicted in Table 3 , half of the patients presented with stage I neoplasms (50.3\%) and, among stages II and III, most of the patients were low IGCCG risk (68.2\%). Seminoma was the most frequent histological type $(50.3 \%)$. The most frequent chemotherapy treatment used was Bleomycin, Etoposide and Cisplatin (BEP) (42.8\%) followed by Etoposide and Cisplatin (EP) (9.7\%) and $44.8 \%$ of the patients did no receive chemotherapy. The median follow up was 40.3 months and the majority of patients were alive and free of disease at the end of the study $(85.9 \%)$.

The present study was approved by the Local Ethic Committee (number 541235).

\section{TMA construction and validation}

All the cases were reviewed by an experienced pathologist (ECAS) for diagnostic confirmation and demarcation of tumor areas for TMA cores. Each tumor histological subtype and corresponding normal tissues were selected (when available and sufficient) for triplicate 
$n(\%)$

\begin{tabular}{lc}
\hline Histological type & \\
Yolk sac & $1(0.7)$ \\
Choriocarcinoma & $2(1.3)$ \\
Embryonal Carcinoma & $8(5.4)$ \\
Immature Teratoma (grade I) & $2(1.3)$ \\
Seminoma & $75(50.3)$ \\
Mixed GCT & $41(27.5)$ \\
Stage at diagnosis & \\
I & $74(50.3)$ \\
II & $35(23.8)$ \\
III & $31(21.1)$ \\
IV & $0(0.0)$ \\
IS & $7(4.8)$ \\
IGCCG Risk & \\
Low & \\
Intermediate & $45(68.2)$ \\
High & $11(16.7)$ \\
Chemotherapy & $10(15.2)$ \\
BEP & \\
Other & $62(42.8)$ \\
No Chemotherapy & $14(9.7)$ \\
Status - post treatment & $4(2.8)$ \\
Alive and disease free & $65(44.8)$ \\
Cancer related death & \\
Death from other causes & $128(85.9)$ \\
\hline & $5(3.4)$ \\
\hline
\end{tabular}

cores of $1.0 \mathrm{~mm}$. Tissue cores of liver, kidney and placenta were used as controls for TMA orientation.

For TMA validation, 31 cases were randomly selected based on sample calculation, with a confidence interval of $95 \%$. For these 31 cases, immunohistochemistry was performed on both TMA and whole sections, and the results compared.

\section{Immunohistochemistry}

Immunohistochemistry was performed on TMA samples and whole sections, according to manufacturer's instructions and as previously described [19]. MCT1 immunohistochemistry was performed using a polymer system (UltraVision LP Detection System: HRP Polymer, Lab Vision Corporation, Fremont, CA). MCT2 and MCT4 immunohistochemistry was performed using the streptavidin-biotin-peroxidase complex principle (Ultravision Detection System: Anti-polyvalent, HRP,
Lab Vision Corporation, Fremont, CA). For CD147, the avidin-biotin-peroxidase complex method (VECTASTAIN Elite ABC kit R.T.U., Vector, Burlingame, CA) was used. For details on each antibody, see Table 4. Slides were counterstained with hematoxylin and permanently mounted. Colon carcinoma tissue was used as positive control for all antibodies.

Plasma membrane expression was evaluated semiquantitatively for extension and semi-qualitatively for intensity. For extension, the grading was: 0: no positive cells; $1:<5 \%$ of positive cells; $2: 5-50 \%$ of positive cells; 3: $>50 \%$ of positive cells. Staining intensity was graded as follows: 0 : negative; 1: weak; 2: moderate; 3 : intense. The final score was obtained by the sum of both grades (minimum 0 and maximum 6).

TMA and whole sections immunostains were evaluated by two experienced pathologists independently (ECAS and CS-N). Discordant cases were reviewed and scored in consensus. 
Table 4: Detailed aspects for each antibody used in immunohistochemistry

\begin{tabular}{|c|c|c|c|}
\hline Protein & Antigen retrieval & Antibody & $\begin{array}{l}\text { Antibody dilution and } \\
\text { incubation time }\end{array}$ \\
\hline MCT1 & Citrate buffer $(0.01 \mathrm{M}, \mathrm{pH}=6), 98^{\circ} \mathrm{C}, 20^{\prime}$ & $\begin{array}{c}\text { AB3538P } \\
\text { Chemicon International }\end{array}$ & $1: 1000$, overnight \\
\hline MCT2 & Citrate buffer $(0.01 \mathrm{M}, \mathrm{pH}=6), 98^{\circ} \mathrm{C}, 20$ & $\begin{array}{c}\text { sc-50322 } \\
\text { Santa Cruz Biotechnology }\end{array}$ & $1: 200,2$ hours \\
\hline MCT4 & Citrate buffer $(0.01 \mathrm{M}, \mathrm{pH}=6), 98^{\circ} \mathrm{C}, 20^{\prime}$ & $\begin{array}{c}\text { sc-50329 } \\
\text { Santa Cruz Biotechnology }\end{array}$ & $1: 500,2$ hours \\
\hline CD147 & EDTA $(1 \mathrm{mM}, \mathrm{pH}=8), 98^{\circ} \mathrm{C}, 20^{\prime}$ & $\begin{array}{c}\text { sc-71038 } \\
\text { Santa Cruz Biotechnology }\end{array}$ & 1:400, overnight \\
\hline
\end{tabular}

\section{Cell lines and cell culture}

The germ cell tumor cell lines NTERA-2 and JEG3 were used in this study. Both cell lines were used for protein characterization using immunocytochemistry and Western Blotting and JEG-3 cell line was used for in vitro studies. The cell lines were maintained in Dulbecco's Modified Eagle's Medium (DMEM 1×, High Glucose, Gibco, Invitrogen) supplemented with $10 \%$ fetal bovine serum, FBS (Gibco, Invitrogen) and $1 \%$ penicillinstreptomycin solution (Gibco, Invitrogen) at $37^{\circ} \mathrm{C}$ and $5 \%$ $\mathrm{CO}_{2}$. The cells were authenticated by genotyping (panel of 8 short tandem repeat loci) as previously described [65], and validated as mycoplasma negative.

\section{Paraffin cytoblock and immunocytochemistry}

Paraffin cytoblocks were made from concentrated cell suspensions by centrifuging fresh cell suspensions at $1500 \mathrm{rpm}$ for $5 \mathrm{~min}$. Cell pellets were incubated with formaldehyde $10 \%$ for 1 hour and recentrifuged. Fixed pellets were included in agarose $2 \%$ PBS $1 \times$ at $60^{\circ} \mathrm{C}$, homogenized and centrifuged at $13000 \mathrm{rpm}$ for $2 \mathrm{~min}$. Solid agarose cell pellets were cuted in two halfs for processing and paraffin inclusion. Immunocytochemistry for MCT1, MCT2, MCT4 and CD147 was performed in $4 \mu \mathrm{m}$ cytoblock sections, as described for immunohistochemistry for human samples.

\section{Western blotting}

NTERA-2 and JEG-3 GCTs cell lines were grown to $70-80 \%$ confluence, washed in cold PBS and then scrapped and homogenized in lysis buffer containing 50 $\mathrm{mM}$ Tris $(\mathrm{pH}=7.5), 150 \mathrm{mM} \mathrm{NaCl}, 0.1 \mathrm{mM}$ EDTA, $1 \%$ Triton X-100 and 1\% NP40, supplemented with 1:10 protease inhibitors (cOmplete Protease Inhibitor Cocktail, Roche) according to the manufacturer's instructions. The lysates were incubated on ice for $15 \mathrm{~min}$ and then centrifuged at $13000 \mathrm{rpm}$ for $15 \mathrm{~min}$ at $4^{\circ} \mathrm{C}$. The supernatants were collected and protein concentration was determined using the Bradford assay (Bio-Rad Protein Assay kit, Bio-Rad). Proteins were dissolved in sample buffer (Laemmli $2 \times$ Concentrate, Sigma-Aldrich) and boiled for $5 \mathrm{~min}$ at $95^{\circ} \mathrm{C}$. Aliquots of $20 \mu \mathrm{g}$ of total protein were separated on $10 \%$ polyacrylamide gel by SDS-PAGE and transferred onto a nitrocellulose membrane (Protran, Amersham, GE Healthcare) in $25 \mathrm{mM}$ Tris-base/glycine buffer by TransBlot Turbo transfer (Bio-Rad). Membranes were blocked with $5 \%$ non-fat dry milk in TBS/0.1\% Tween (TBS- $\mathrm{T} ; \mathrm{pH}=7.6$ ) for 1 hour at room temperature. After overnight incubation at $4^{\circ} \mathrm{C}$ with the primary antibodies (dilution in TBS-T, 5\% BSA) for MCT1 (1:200 dilution, H-1, sc-365501, Santa Cruz Biotechnology), MCT2 (1:1200 dilution, ab81262, Abcam), MCT4 (1:2000 dilution, H-90, sc-50329, Santa Cruz Biotechnology) and CD147 (1:250 dilution, 1.BB.218, sc-71038, Santa Cruz Biotechnology), membranes were washed in TBS-T and incubated with anti-rabbit (sc-2020, Santa Cruz Biotechnology) or anti-mouse (sc-2031, Santa Cruz Biotechnology) secondary antibodies coupled to horseradish peroxidase (1:5000 dilution in TBS-T, 5\% non-fat dry milk). The bound antibodies were visualized by chemiluminescence (Supersignal West Femto kit, Pierce) in ImageQuant LAS 4000 mini (GE Healthcare). $\beta$-Actin was used as loading control at 1:2000 dilution (8H10D10, Cell Signaling Technology).

\section{RNA interference and transfection}

Silencing experiments were performed using $10 \mathrm{nM}$ of Silencer Select Validated siRNA for MCT1 (SLC16A1 siRNA, s580, Ambion) and MCT4 (SLC16A3 siRNA, s17417, Ambion), as well as nontargeting control siRNA (Silencer Select Negative Control No.1 siRNA, 4390843, Ambion), using $1 \mu \mathrm{l} / \mathrm{ml}$ of Lipofectamine RNAiMAX (13778-075, Invitrogen), according to the manufacturer's instructions. For MCT1, total silencing was only observed after 1 day, with the reestablishment of the MCT1 expression at day 2 (48 hours, confirmed by Western Blot, Supplementary Figure 1A). For MCT4, total silencing was only observed after 72 hours, being maintained for at least 2 additional days (120 hours, confirmed by Western Blot, Supplementary Figure 1B and 1C). The cells were plated at day 3 after silencing, when the experiments begin. 


\section{Cell biomass analysis}

The effect of MCT4 knockdown on total biomass was measured by the Sulforhodamine B assay (TOX6 , Sigma-Aldrich), according to the manufacturer's instructions. For that, $1.0 \times 10^{4} \mathrm{cells} /$ well of silenced and negative control cells were plated in 96-wells plates in complete DMEM medium culture. Total biomass was quantified after 24 hours. Results are represented as percentage of total biomass normalized for the control condition, of three independent experiments, in triplicate.

\section{Metabolism assay (extracellular glucose and lactate measurements)}

The metabolic behavior of MCT4 knockdown JEG3 cell line was determined by analyzing the extracellular amounts of glucose and lactate. For that, $1.0 \times 10^{4}$ cells/ well of silenced and negative control cells were plated in 96-wells plates in complete DMEM medium culture. Glucose and lactate measurement were performed after 24 hours, with commercial kits (Cayman Chemical and SpinReact, respectively), according to the manufacturer's instructions. Results are expressed as total $\mu \mathrm{g} /$ total biomass of three independent experiments, in triplicate.

\section{Cell proliferation assay}

The proliferation capacity after silencing of MCT4 on JEG-3 cell line was assessed by bromodeoxyuridine incorporation. For that, $1.0 \times 10^{4}$ cells/well of silenced and negative control cells were plated in 96-wells plates in complete DMEM medium culture. To determine the percentage of proliferation, cells were incubated with 10 $\mu \mathrm{M}$ bromodeoxyuridine for 24 hours and its incorporation was assessed at $370 \mathrm{~nm}\left(\lambda_{\text {ref }}=492 \mathrm{~nm}\right)$, according to the manufacturer's protocol (Cell Proliferation ELISA, BrdU, Roche). Results are represented as percentage of proliferation normalized for the control condition, of at least three independent experiments, in triplicate.

\section{Cell death assay}

Apoptotic/necrotic cell population was determined by Annexin V-FITC Apoptosis Detection Kit I (BD Biosciences) according to the manufacturer's instructions. For that, $4.0 \times 10^{5}$ cells/well of silenced and negative control cells were plated in 6-wells plates in complete DMEM medium culture. After 24 hours, cells were collected and Annexin V/PI staining was performed with incubation for $15 \mathrm{~min}$ at room temperature. The percentage of cell death (double staining) was assessed by flow cytometry (BD Accuri C6, BD Biosciences), with a total of 20000 events collected for each condition. Results were analyzed using the BD Accuri C6 Software (version 1.0.264.21) and are represented as percentage of cell death normalized for the control condition, of two independent experiments.

\section{Migration assay}

Migration capacity of JEG-3 cell line was measured using ThinCert Cell Cultures Inserts (Greiner Bio-One), according to the manufacturer's instructions. In brief, $1.0 \times 10^{5} \mathrm{cells} / \mathrm{well}$ of silenced and negative control cells were plated in 24-well transwell inserts in DMEM, 0\% FBS. DMEM supplemented with $10 \%$ FBS was used as chemoattractant. Cells were allowed to migrate for 24 hours. Then, the cells that did not migrate were removed and migrating cells were fixed with methanol and stained with hematoxylin and eosin for $10 \mathrm{~min}$. Membranes were photographed in Olympus BX43 $(\times 10$ magnification), and migrating cells were counted using the OpenCFU software (version 3.8) [66]. Results are represented as percentage of cell migration normalized for the control condition, of two independent experiments in duplicate.

\section{Invasion assay}

Invasion capacity of JEG-3 cell line was measured using Corning BioCoat Matrigel Invasion Chamber with BD Matrigel Matrix (Corning), as indicated by the manufacturer. In brief, $2.5 \times 10^{5}$ cells/well of silenced and negative control cells were plated in the matrigel-coated 24-well transwell inserts in DMEM, 0\% FBS. DMEM supplemented with $10 \%$ FBS was used as chemoattractant. Cells were allowed to invade for 24 hours. Then, the noninvading cells were removed and invading cells were fixed with methanol and stained with hematoxylin and eosin for $10 \mathrm{~min}$. Membranes were photographed in Olympus BX43 ( $\times 10$ magnification), and invading cells were counted using the OpenCFU software (version 3.8) [66]. Results are represented as percentage of cell invasion normalized for the control condition, of at least three independent experiments in duplicate.

\section{Statistical analysis}

Results obtained with the human samples were analyzed using IBM SPSS Statistics software (version 23.0, IBM Company, Armonk, NY). ROC curve was used to define final score's cutoff for positivity, based on the area under the curve. Frequency of protein expression and comparison with clinicopathological data were analyzed using McNemar's test, Pearson's chi-square test and Fisher's exact test, according to the sample's characteristics. The agreement between TMA and whole sections was evaluated by the accuracy of the method. Overall and event-free survival curves were constructed using Kaplan-Meier's method and the data compared with log-rank test. Cox regression model was used for multivariate analysis. In vitro results were analyzed 
using GraphPad Prism software (version 6.0, GraphPad Software, Inc., La Jolla, CA), with Student's $t$ test (Welch's correction was used in case of unequal variances). For all tests, the level of significance was established as 5\% (significant results if $p<0.05$ ).

\section{CONFLICTS OF INTEREST}

The authors declare no conflicts of interest.

\section{GRANT SUPPORT}

This study was supported by CNPq, Conselho Nacional de Desenvolvimento Científico e Tecnológico, Brasil (480119/2013-9 and 306195/2016-0).

\section{REFERENCES}

1. Schneider DT, Calaminus G, Koch S, Teske C, Schmidt P, Haas RJ, Harms D, Gobel U. Epidemiologic analysis of 1,442 children and adolescents registered in the German germ cell tumor protocols. Pediatr Blood Cancer. 2004; 42:169-175.

2. Nallu A, Mannuel HD, Hussain A. Testicular germ cell tumors: biology and clinical update. Curr Opin Oncol. 2013; 25:266-272.

3. Hanna N, Einhorn LH. Testicular cancer: a reflection on 50 years of discovery. J Clin Oncol. 2014; 32:3085-3092.

4. Rajpert-De Meyts E, McGlynn KA, Okamoto K, Jewett MA, Bokemeyer C. Testicular germ cell tumours. Lancet. 2016; 387:1762-1774.

5. Litchfield K, Levy M, Huddart RA, Shipley J, Turnbull C. The genomic landscape of testicular germ cell tumours: from susceptibility to treatment. Nat Rev Urol. 2016; 13:409-419.

6. Hanahan D, Weinberg RA. Hallmarks of cancer: the next generation. Cell. 2011; 144:646-674.

7. Pavlova NN, Thompson CB. The Emerging Hallmarks of Cancer Metabolism. Cell Metab. 2016; 23:27-47.

8. Vander Heiden MG, Cantley LC, Thompson CB. Understanding the Warburg effect: the metabolic requirements of cell proliferation. Science. 2009; 324:1029-1033.

9. Warburg O. On the origin of cancer cells. Science. 1956; 123:309-314.

10. Izumi $\mathrm{H}$, Torigoe $\mathrm{T}$, Ishiguchi $\mathrm{H}$, Uramoto $\mathrm{H}$, Yoshida Y, Tanabe M, Ise T, Murakami T, Yoshida T, Nomoto M, Kohno K. Cellular $\mathrm{pH}$ regulators: potentially promising molecular targets for cancer chemotherapy. Cancer Treat Rev. 2003; 29:541-549.

11. Halestrap AP. The monocarboxylate transporter familyStructure and functional characterization. IUBMB Life. 2012; 64:1-9.
12. Enerson BE, Drewes LR. Molecular features, regulation, and function of monocarboxylate transporters: implications for drug delivery. J Pharm Sci. 2003; 92:1531-1544.

13. Kirk P, Wilson MC, Heddle C, Brown MH, Barclay AN, Halestrap AP. CD147 is tightly associated with lactate transporters MCT1 and MCT4 and facilitates their cell surface expression. EMBO J. 2000; 19:3896-3904.

14. Lin RY, Vera JC, Chaganti RS, Golde DW. Human monocarboxylate transporter 2 (MCT2) is a high affinity pyruvate transporter. J Biol Chem. 1998; 273:28959-28965.

15. Wilson MC, Meredith D, Fox JE, Manoharan C, Davies AJ, Halestrap AP. Basigin (CD147) is the target for organomercurial inhibition of monocarboxylate transporter isoforms 1 and 4: the ancillary protein for the insensitive MCT2 is EMBIGIN (gp70). J Biol Chem. 2005; 280:27213-27221.

16. Kim Y, Choi JW, Lee JH, Kim YS. Expression of lactate/H(+) symporters MCT1 and MCT4 and their chaperone CD147 predicts tumor progression in clear cell renal cell carcinoma: immunohistochemical and The Cancer Genome Atlas data analyses. Hum Pathol. 2015; 46:104-112.

17. Pinheiro C, Longatto-Filho A, Azevedo-Silva J, Casal M, Schmitt FC, Baltazar F. Role of monocarboxylate transporters in human cancers: state of the art. J Bioenerg Biomembr. 2012; 44:127-139.

18. Bovenzi CD, Hamilton J, Tassone P, Johnson J, Cognetti DM, Luginbuhl A, Keane WM, Zhan T, Tuluc M, Bar-Ad V, Martinez-Outschoorn U, Curry JM. Prognostic Indications of Elevated MCT4 and CD147 across Cancer Types: A Meta-Analysis. Biomed Res Int. 2015; 2015:242437.

19. Pinheiro C, Granja S, Longatto-Filho A, Faria AM, Fragoso MC, Lovisolo SM, Lerario AM, Almeida MQ, Baltazar F, Zerbini MC. Metabolic reprogramming: a new relevant pathway in adult adrenocortical tumors. Oncotarget. 2015; 6:44403-44421. https://doi.org/10.18632/oncotarget.5623.

20. Martins SF, Amorim R, Viana-Pereira M, Pinheiro C, Costa RF, Silva P, Couto C, Alves S, Fernandes S, Vilaca S, Falcao J, Marques H, Pardal F, et al. Significance of glycolytic metabolism-related protein expression in colorectal cancer, lymph node and hepatic metastasis. BMC Cancer. 2016; 16:535.

21. Simoes-Sousa S, Granja S, Pinheiro C, Fernandes D, Longatto-Filho A, Laus AC, Alves CD, Suarez-Penaranda JM, Perez-Sayans M, Lopes Carvalho A, Schmitt FC, Garcia-Garcia A, Baltazar F. Prognostic significance of monocarboxylate transporter expression in oral cavity tumors. Cell Cycle. 2016; 15:1865-1873.

22. Pinheiro C, Miranda-Goncalves V, Longatto-Filho A, Vicente AL, Berardinelli GN, Scapulatempo-Neto C, Costa RF, Viana CR, Reis RM, Baltazar F, Vazquez VL. The metabolic microenvironment of melanomas: Prognostic value of MCT1 and MCT4. Cell Cycle. 2016; 15:1462-1470.

23. Gao HJ, Zhao MC, Zhang YJ, Zhou DS, Xu L, Li GB, Chen MS, Liu J. Monocarboxylate transporter 4 predicts poor 
prognosis in hepatocellular carcinoma and is associated with cell proliferation and migration. J Cancer Res Clin Oncol. 2015; 141:1151-62.

24. Baltazar F, Pinheiro C, Morais-Santos F, Azevedo-Silva J, Queiros O, Preto A, Casal M. Monocarboxylate transporters as targets and mediators in cancer therapy response. Histol Histopathol. 2014; 29:1511-1524.

25. Mathupala SP, Parajuli P, Sloan AE. Silencing of monocarboxylate transporters via small interfering ribonucleic acid inhibits glycolysis and induces cell death in malignant glioma: an in vitro study. Neurosurgery. 2004; 55:1410-1419; discussion 1419.

26. Sonveaux P, Vegran F, Schroeder T, Wergin MC, Verrax J, Rabbani ZN, De Saedeleer CJ, Kennedy KM, Diepart C, Jordan BF, Kelley MJ, Gallez B, Wahl ML, et al. Targeting lactate-fueled respiration selectively kills hypoxic tumor cells in mice. J Clin Invest. 2008; 118:3930-3942.

27. Schneiderhan W, Scheler M, Holzmann KH, Marx M, Gschwend JE, Bucholz M, Gress TM, Seufferlein T, Adler G, Oswald F. CD147 silencing inhibits lactate transport and reduces malignant potential of pancreatic cancer cells in in vivo and in vitro models. Gut. 2009; 58:1391-1398.

28. Morais-Santos F, Granja S, Miranda-Goncalves V, Moreira AH, Queiros S, Vilaca JL, Schmitt FC, Longatto-Filho A, Paredes J, Baltazar F, Pinheiro C. Targeting lactate transport suppresses in vivo breast tumour growth. Oncotarget. 2015; 6:19177-19189. https://doi.org/10.18632/oncotarget.3910.

29. Granja S, Marchiq I, Le Floch R, Moura CS, Baltazar F, Pouysségur J. Disruption of BASIGIN decreases lactic acid export and sensitizes non-small cell lung cancer to biguanides independently of the LKB1 status. Oncotarget. 2015; 6:6708-6721. https://doi.org/10.18632/ oncotarget.2862.

30. Marchiq I, Le Floch R, Roux D, Simon MP, Pouyssegur J. Genetic Disruption of Lactate/H+ Symporters (MCTs) and their Subunit CD147/BASIGIN Sensitizes Glycolytic Tumor Cells to Phenformin. Cancer Res. 2015; 75:171-80.

31. Parks SK, Chiche J, Pouyssegur J. Disrupting proton dynamics and energy metabolism for cancer therapy. Nat Rev Cancer. 2013; 13:611-623.

32. Howitt BE, Brooks JD, Jones S, Higgins JP. Identification and characterization of 2 testicular germ cell markers, Glut3 and CyclinA2. Appl Immunohistochem Mol Morphol. 2013; 21:401-407.

33. Younes M, Lechago LV, Somoano JR, Mosharaf M, Lechago J. Immunohistochemical detection of Glut3 in human tumors and normal tissues. Anticancer Res. 1997; 17:2747-2750.

34. Vander Heiden MG. Targeting cancer metabolism: a therapeutic window opens. Nat Rev Drug Discov. 2011; 10:671-684.

35. Cremerius U, Wildberger JE, Borchers H, Zimny M, Jakse G, Gunther RW, Buell U. Does positron emission tomography using 18-fluoro-2-deoxyglucose improve clinical staging of testicular cancer?-Results of a study in 50 patients. Urology. 1999; 54:900-904.

36. Oechsle K, Hartmann M, Brenner W, Venz S, Weissbach L, Franzius C, Kliesch S, Mueller S, Krege S, Heicappell R, Bares R, Bokemeyer C, de Wit M, German Multicenter Positron Emission Tomography Study Group. [18F] Fluorodeoxyglucose positron emission tomography in nonseminomatous germ cell tumors after chemotherapy: the German multicenter positron emission tomography study group. J Clin Oncol. 2008; 26:5930-5935.

37. Bachner M, Loriot Y, Gross-Goupil M, Zucali PA, Horwich A, Germa-Lluch JR, Kollmannsberger C, Stoiber F, Flechon A, Oechsle K, Gillessen S, Oldenburg J, Cohn-Cedermark $\mathrm{G}$, et al. 2-(1)(8)fluoro-deoxy-D-glucose positron emission tomography (FDG-PET) for postchemotherapy seminoma residual lesions: a retrospective validation of the SEMPET trial. Ann Oncol. 2012; 23:59-64.

38. Pinheiro C, Longatto-Filho A, Ferreira L, Pereira SM, Etlinger D, Moreira MA, Jube LF, Queiroz GS, Schmitt F, Baltazar F. Increasing expression of monocarboxylate transporters 1 and 4 along progression to invasive cervical carcinoma. Int J Gynecol Pathol. 2008; 27:568-574.

39. Pinheiro C, Longatto-Filho A, Scapulatempo C, Ferreira L, Martins S, Pellerin L, Rodrigues M, Alves VA, Schmitt F, Baltazar F. Increased expression of monocarboxylate transporters 1, 2, and 4 in colorectal carcinomas. Virchows Arch. 2008; 452:139-146.

40. Pinheiro C, Garcia EA, Morais-Santos F, ScapulatempoNeto C, Mafra A, Steenbergen RD, Boccardo E, Villa LL, Baltazar F, Longatto-Filho A. Lactate transporters and vascular factors in HPV-induced squamous cell carcinoma of the uterine cervix. BMC Cancer. 2014; 14:751.

41. Alves VA, Pinheiro C, Morais-Santos F, Felipe-Silva A, Longatto-Filho A, Baltazar F. Characterization of monocarboxylate transporter activity in hepatocellular carcinoma. World J Gastroenterol. 2014; 20:11780-11787.

42. Pinheiro C, Penna V, Morais-Santos F, Abrahao-Machado LF, Ribeiro G, Curcelli EC, Olivieri MV, Morini S, Valenca I, Ribeiro D, Schmitt FC, Reis RM, Baltazar F. Characterization of monocarboxylate transporters (MCTs) expression in soft tissue sarcomas: distinct prognostic impact of MCT1 sub-cellular localization. J Transl Med. 2014; $12: 118$.

43. Miranda-Goncalves V, Honavar M, Pinheiro C, Martinho O, Pires MM, Pinheiro C, Cordeiro M, Bebiano G, Costa P, Palmeirim I, Reis RM, Baltazar F. Monocarboxylate transporters (MCTs) in gliomas: expression and exploitation as therapeutic targets. Neuro Oncol. 2013; 15:172-188.

44. Pinheiro C, Longatto-Filho A, Soares TR, Pereira H, Bedrossian C, Michael C, Schmitt FC, Baltazar F. CD147 immunohistochemistry discriminates between reactive mesothelial cells and malignant mesothelioma. Diagn Cytopathol. 2012; 40:478-483.

45. de Oliveira AT, Pinheiro C, Longatto-Filho A, Brito MJ, Martinho O, Matos D, Carvalho AL, Vazquez VL, Silva 
TB, Scapulatempo C, Saad SS, Reis RM, Baltazar F. Co-expression of monocarboxylate transporter 1 (MCT1) and its chaperone (CD147) is associated with low survival in patients with gastrointestinal stromal tumors (GISTs). J Bioenerg Biomembr. 2012; 44:171-178.

46. Pertega-Gomes N, Vizcaino JR, Miranda-Goncalves V, Pinheiro C, Silva J, Pereira H, Monteiro P, Henrique RM, Reis RM, Lopes C, Baltazar F. Monocarboxylate transporter 4 (MCT4) and CD147 overexpression is associated with poor prognosis in prostate cancer. BMC Cancer. 2011; 11:312.

47. Pinheiro C, Reis RM, Ricardo S, Longatto-Filho A, Schmitt F, Baltazar F. Expression of monocarboxylate transporters 1,2 , and 4 in human tumours and their association with CD147 and CD44. J Biomed Biotechnol. 2010; 2010:427694.

48. Pinheiro C, Albergaria A, Paredes J, Sousa B, Dufloth R, Vieira D, Schmitt F, Baltazar F. Monocarboxylate transporter 1 is up-regulated in basal-like breast carcinoma. Histopathology. 2010; 56:860-867.

49. Pinheiro C, Longatto-Filho A, Simoes K, Jacob CE, Bresciani CJ, Zilberstein B, Cecconello I, Alves VA, Schmitt F, Baltazar F. The prognostic value of CD147/ EMMPRIN is associated with monocarboxylate transporter 1 co-expression in gastric cancer. Eur J Cancer. 2009; 45:2418-2424.

50. Pinheiro C, Longatto-Filho A, Pereira SM, Etlinger D, Moreira MA, Jube LF, Queiroz GS, Schmitt F, Baltazar F. Monocarboxylate transporters 1 and 4 are associated with CD147 in cervical carcinoma. Dis Markers. 2009; 26:97-103.

51. Pinheiro C, Garcia EA, Morais-Santos F, Moreira MA, Almeida FM, Jube LF, Queiroz GS, Paula EC, Andreoli MA, Villa LL, Longatto-Filho A, Baltazar F. Reprogramming energy metabolism and inducing angiogenesis: co-expression of monocarboxylate transporters with VEGF family members in cervical adenocarcinomas. BMC Cancer. 2015; 15:835.

52. Sangoi AR, McKenney JK, Brooks JD, Higgins JP. Evaluation of SF-1 expression in testicular germ cell tumors: a tissue microarray study of 127 cases. Appl Immunohistochem Mol Morphol. 2013; 21:318-321.

53. Fankhauser CD, Curioni-Fontecedro A, Allmann V, Beyer J, Tischler V, Sulser T, Moch H, Bode PK. Frequent PD-L1 expression in testicular germ cell tumors. Br J Cancer. 2015; 113:411-413.

54. Ohno A, Yorita K, Haruyama Y, Kondo K, Kato A, Ohtomo T, Kawaguchi M, Marutuska K, Chijiiwa K, Kataoka H. Aberrant expression of monocarboxylate transporter 4 in tumour cells predicts an unfavourable outcome in patients with hepatocellular carcinoma. Liver Int. 2014; 34:942-952.

55. Klier M, Schuler C, Halestrap AP, Sly WS, Deitmer JW, Becker HM. Transport activity of the high-affinity monocarboxylate transporter MCT2 is enhanced by extracellular carbonic anhydrase IV but not by intracellular carbonic anhydrase II. J Biol Chem. 2011; 286:27781-27791.
56. Doyen J, Trastour C, Ettore F, Peyrottes I, Toussant N, Gal J, Ilc K, Roux D, Parks SK, Ferrero JM, Pouyssegur J. Expression of the hypoxia-inducible monocarboxylate transporter MCT4 is increased in triple negative breast cancer and correlates independently with clinical outcome. Biochem Biophys Res Commun. 2014; 451:54-61.

57. Choi JW, Kim Y, Lee JH, Kim YS. Prognostic significance of lactate/proton symporters MCT1, MCT4, and their chaperone CD147 expressions in urothelial carcinoma of the bladder. Urology. 2014; 84:245 e249-215.

58. Meijer TW, Schuurbiers OC, Kaanders JH, Looijen-Salamon MG, de Geus-Oei LF, Verhagen AF, Lok J, van der Heijden HF, Rademakers SE, Span PN, Bussink J. Differences in metabolism between adeno- and squamous cell non-small cell lung carcinomas: spatial distribution and prognostic value of GLUT1 and MCT4. Lung Cancer. 2012; 76:316-323.

59. Zhu J, Wu YN, Zhang W, Zhang XM, Ding X, Li HQ, Geng M, Xie ZQ, Wu HM. Monocarboxylate transporter 4 facilitates cell proliferation and migration and is associated with poor prognosis in oral squamous cell carcinoma patients. PLoS One. 2014; 9:e87904.

60. Gray AL, Coleman DT, Shi R, Cardelli JA. Monocarboxylate transporter 1 contributes to growth factor-induced tumor cell migration independent of transporter activity. Oncotarget. 2016; 7:32695-32706. https://doi.org/10.18632/ oncotarget.9016.

61. Gallagher SM, Castorino JJ, Philp NJ. Interaction of monocarboxylate transporter 4 with betal-integrin and its role in cell migration. Am J Physiol Cell Physiol. 2009; 296:C414-421.

62. Kong SC, Nohr-Nielsen A, Zeeberg K, Reshkin SJ, Hoffmann EK, Novak I, Pedersen SF. Monocarboxylate Transporters MCT1 and MCT4 Regulate Migration and Invasion of Pancreatic Ductal Adenocarcinoma Cells. Pancreas. 2016; 45:1036-1047.

63. De Saedeleer CJ, Porporato PE, Copetti T, Perez-Escuredo J, Payen VL, Brisson L, Feron O, Sonveaux P. Glucose deprivation increases monocarboxylate transporter 1 (MCT1) expression and MCT1-dependent tumor cell migration. Oncogene. 2014; 33:4060-4068.

64. Izumi H, Takahashi M, Uramoto H, Nakayama Y, Oyama T, Wang KY, Sasaguri Y, Nishizawa S, Kohno K. Monocarboxylate transporters 1 and 4 are involved in the invasion activity of human lung cancer cells. Cancer Sci. 2011; 102:1007-1013.

65. Silva-Oliveira RJ, Silva VA, Martinho O, Cruvinel-Carloni A, Melendez ME, Rosa MN, de Paula FE, de Souza Viana L, Carvalho AL, Reis RM. Cytotoxicity of allitinib, an irreversible anti-EGFR agent, in a large panel of human cancer-derived cell lines: KRAS mutation status as a predictive biomarker. Cell Oncol (Dordr). 2016; 39:253-263.

66. Geissmann Q. OpenCFU, a new free and open-source software to count cell colonies and other circular objects. PLoS One. 2013; 8:e54072. 